\title{
Study on the oxidation and acid corrosion of the black shale
}

\author{
Jian $\mathrm{LI}^{1, \mathrm{a}}$, Ruyu HUANG${ }^{2, \mathrm{~b}}$, Xin $\mathrm{LIAO}^{3, \mathrm{c}^{*}}$ and Xiyong WU $\mathrm{W}^{4, \mathrm{~d}}$ \\ ${ }^{1}$ Chongqing Jiaotong University, Chongqing city, China \\ 2,3,4 Department of geology in Southwest Jiaotong University, Chengdu city, China \\ a17639336@qq.com, ${ }^{b} 316352126 @ q q . c o m,{ }^{*}$ starwen.05@163.com, dwuxiyong@126.com,
}

Keywords: black shale, oxidation, acid corrosion

Abstract. The Qingxi Formation black shales which are distributed in Sanjiang region of Guangxi province, China, are studied as the object in this paper. The mineralogical and chemical compositions of rock and weathering product samples were determined by X-ray diffraction and $\mathrm{X}$-ray fluorescence spectrometer. According to the chemical reactions involved in the black shale oxidation process, the corrosion impact of acidic aqueous solution produced by the black shale chemical weathering on the concrete components were analyzed. Furthermore, the sulfate minerals as the significant weathering products are characterized by volume expansion in the cyclic wet-dry environment. It is indicated that black shale oxidation process can bring acid corrosion to the surrounding rocks and construction materials.

\section{Introduction}

Black shale's oxidation and acid corrosion is not only chemical weathering process, but also common form of water-rock reaction ${ }^{[1-2]}$. With the development of engineering construction for the past few years, more and more deformation-failure phenomenon was observed on the black shale slope. It is inferred to be associated with the black shale's oxidation and acid corrosion reaction. Pyrite contained in the black shale was oxidized immediately by the dissolved oxygen and ferric ion to produce strongly acidic water, which could result in corrosion of unstable minerals. As oxidation and acid corrosion proceeded, the minerals composition and mechanical property changed accordingly. Based on the previous black shale weathering researches, the weathering products can be divided into several categories ${ }^{[3-5]}$ : 1) acidic water; 2) sulfate minerals; 3) iron oxides and hydroxides; 4) clay minerals; 5) heavy metal and trace elements, etc. Corrosive acid water is produced in the weathering process. It can affect rock components, texture and structure in a short time and even for that of the construction materials nearby ${ }^{[6]}$. This study regarded the black shale distributed in Sanjiang region, Guangxi province, China, as research objects. The mineralogical and chemical compositions of black shale as well as the features of weathering products were analyzed to illustrate the mechanism of oxidation and acid corrosion.

\section{Mineral and chemical properties}

The Qingxi formation black shales with lamellated structure were exposed in study area, which is shown in Fig. 1. It is observed that the upper rocks are loose and granulated differentiation, and the lower parts are deposited by weathering fragments. Tawny fissure water seeps from the slope surface. Pyrite was distributed with the dot, strawberry and cryptomere shaped. Acid corrosion phenomenon can be obviously seen on the concrete retailing wall at the bottom of the slope.

Eight representative rock and weathering product samples were selected to determine the major 
mineral and chemical components. The major mineral contents were listed in Table 1. It shows the content of carbonaceous material is approximate $50 \%$ and that of pyrite is less than $2 \%$ in three samples. Attribution to the heterogeneous distribution of pyrite, its content can reach to $29 \%$ in some samples. The chemical composition of the samples taken from the study area was analyzed. The results are shown in Table 2. It shows that the content of silicon dioxide is more than 50\%, following is aluminum oxide about $9 \%$. What's more, the content of iron oxide is about $2 \%$ which is assumed to be pyrite and limonite.

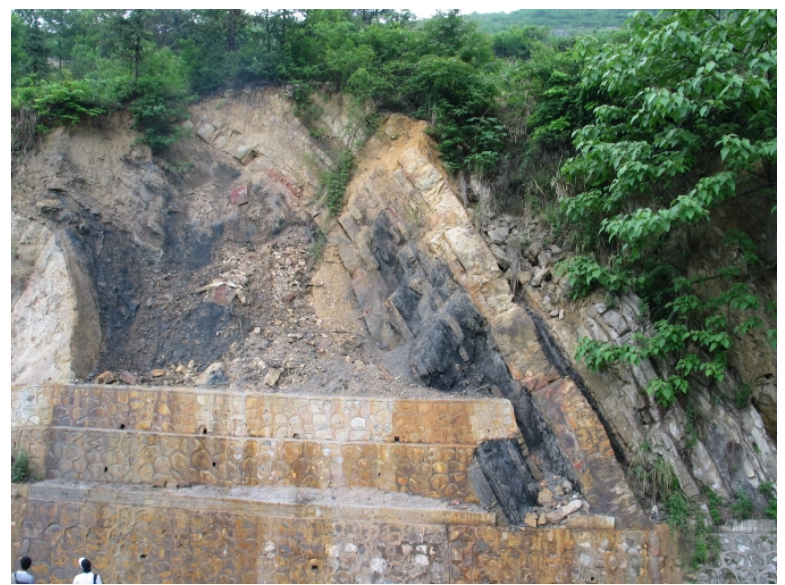

Fig.1 Black shale slope in the study area

Table 1 Main compositions of the Qingxi Formation black shale samples

\begin{tabular}{lllll}
\hline No. & carbonaceous material & quartz & clay & $\mathrm{FeS}_{2}$ \\
\hline 1 & $90 \%$ & $7 \%-8 \%$ & $2 \%-3 \%$ & $<2 \%$ \\
2 & $55 \%-60 \%$ & $35 \%-40 \%$ & $4 \%-5 \%$ & $<2 \%$ \\
3 & $50 \%$ & $45 \%$ & $4 \%-5 \%$ & $<2 \%$ \\
4 & $50 \%-55 \%$ & $15 \%-20 \%$ & $2 \%-3 \%$ & $>25 \%$
\end{tabular}

Table 2 Chemical compositions of the Qingxi Formation black shale samples

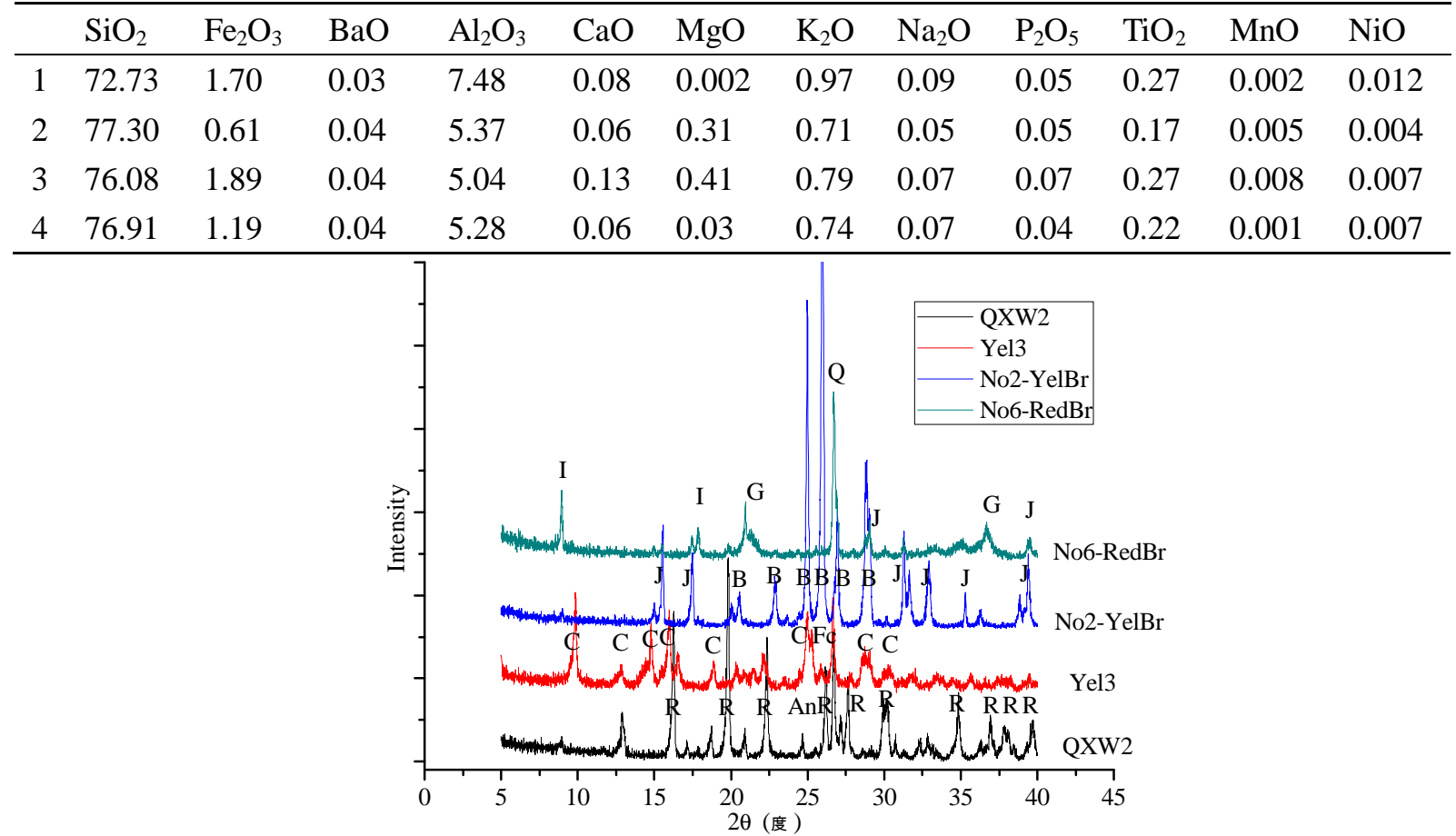

(I)Illite (Q)Quartz (R)Rozenite (J)Jarosite (C)Copiapite (Fc)Ferricopiapite (B) Barite (G) Goethite

Fig. 2 Analysis results of mineral constituents by X-ray diffraction 
Four typical weathering products were analyzed through X-ray diffraction as well (Fig. 2). The white precipitate QXW2 was mainly consist of rozenite $\left(\mathrm{FeSO}_{4} \cdot 4 \mathrm{H}_{2} \mathrm{O}\right)$ and small amount of pyrite and anhydrous gypsum $\left(\mathrm{CaSO}_{4}\right)$; the yellow precipitate Yel3 was mainly consist of copiapite and ferricopiapite with large amounts of crystal water; the yellow-brown precipitate No2-YelBr was mainly consist of barite $\left(\mathrm{BaSO}_{4}\right)$ and jarosite $\left(\mathrm{KFe}_{3}\left(\mathrm{SO}_{4}\right)_{2}(\mathrm{OH})_{6}\right)$; the red-brown precipitate No6-RedBr was mainly consist of goethite $(\mathrm{FeOOH})$ and illite. According to the chemical formula of these weathering products, it indicates that most of them are sulfate minerals bearing with iron and other metal element as well as some iron oxides.

\section{Oxidation-acid corrosion mechanism}

During the black shale chemical weathering processes, hydrogen and sulfate ions produced from the sulfide minerals oxidation can react with the concrete material. The calcium ingredient in cement concrete is susceptible to suffer corrosion damage. The hydrogen ions would react with dicalcium silicate and tricalcium silicate. Concrete acidification can cause the loss of solidified cement components and loose structure on the surface. Acidic water reacts with calcium hydroxide to form gypsum (Eq. 1). The gypsum can be crystallized and expanded. Its crystallization pressure can get to 335 atmospheric pressure at $8^{\circ} \mathrm{C}$.

$$
\mathrm{Ca}(\mathrm{OH})_{2}+\mathrm{H}_{2} \mathrm{SO}_{4} \rightarrow \mathrm{CaSO}_{4} \cdot 2 \mathrm{H}_{2} \mathrm{O}
$$

In our field investigation, it is found that sulfate corrosion proceed predominantly. The concentrations of sulfate and magnesium ions in the fissure water are relative high. Therefore, the magnesium salts react with the calcium hydroxide to form gypsum and epsomite (Eq. 2):

$$
\mathrm{MgSO}_{4}+\mathrm{Ca}(\mathrm{OH})_{2}+2 \mathrm{H}_{2} \mathrm{O} \rightarrow \mathrm{CaSO}_{4} \cdot 2 \mathrm{H}_{2} \mathrm{O}+\mathrm{Mg}(\mathrm{OH})_{2}
$$

With the decrease of calcium hydroxide, hydrated calcium sulfate began to decompose to maintain the $\mathrm{pH}$ of solution. The formed gypsum will produce tensile stress on concrete and lead to structure damage of the concrete. What's more, the sulfate ions produced from pyrite oxidation can react with magnesium and sodium ions as well as to form various sulfate hydrated (Eq. 3, Eq.4):

$$
\begin{aligned}
& \mathrm{Mg}^{2+}+\mathrm{SO}_{4}{ }^{2-}+7 \mathrm{H}_{2} \mathrm{O} \rightarrow \mathrm{MgSO}_{4} \cdot 7 \mathrm{H}_{2} \mathrm{O} \\
& 2 \mathrm{Na}^{+}+\mathrm{SO}_{4}{ }^{2-}+12 \mathrm{H}_{2} \mathrm{O} \rightarrow \mathrm{Na}_{2} \mathrm{SO}_{4} \cdot 12 \mathrm{H}_{2} \mathrm{O}
\end{aligned}
$$

The volume of these hydrates will increase constantly when their saturation is 2 at $8^{\circ} \mathrm{C}$. The expansive force will cause internal tensile stress within the concrete structure as well. Generally, the tensile strength of concrete is about 1/10 times of its compressive strength. Therefore, the concrete structure is easily to be disintegrated and cracked under the crystallization expansion effect.

The chemical equations of the weathering products sampled in our study are shown in Eq.5- Eq.8. It can be seen that there are some crystal water with in rozenite, copiapite and ferricopiapite. They are easily to absorb and loss crystal water under the wetting-drying cycle. Meanwhile, it will bring 
the effect of volume expansion. The volume expansion ratio of the weathering products have been calculated and listed in Table 3.

$$
\begin{aligned}
& \mathrm{Fe}^{2+}+\mathrm{SO}_{4}{ }^{2-}+4 \mathrm{H}_{2} \mathrm{O} \rightarrow \mathrm{FeSO}_{4} \cdot 4 \mathrm{H}_{2} \mathrm{O} \\
& 5 \mathrm{FeSO}_{4} \cdot 4 \mathrm{H}_{2} \mathrm{O}+\mathrm{O}_{2}+\mathrm{H}_{2} \mathrm{SO}_{4} \rightarrow \mathrm{Fe}^{2+} \mathrm{Fe}^{3+}\left(\mathrm{SO}_{4}\right)_{6}(\mathrm{OH})_{2} \cdot 20 \mathrm{H}_{2} \mathrm{O} \\
& 4 \mathrm{Fe}^{2+} \mathrm{Fe}^{3+}\left(\mathrm{SO}_{4}\right)_{6}(\mathrm{OH})_{2} \cdot 20 \mathrm{H}_{2} \mathrm{O}+\mathrm{O}_{2} \rightarrow 4 \mathrm{Fe}_{5}{ }^{3+}\left(\mathrm{SO}_{4}\right)_{6}(\mathrm{OH})_{2} \cdot 20 \mathrm{H}_{2} \mathrm{O}+2 \mathrm{H}_{2} \mathrm{O} \\
& 3 \mathrm{FeO}(\mathrm{OH})+\mathrm{K}^{+}+2 \mathrm{SO}_{4}{ }^{2-}+3 \mathrm{H}^{+} \rightarrow 3 \mathrm{KFe}_{3}\left(\mathrm{SO}_{4}\right)_{2}(\mathrm{OH})_{6}
\end{aligned}
$$

Table 3 Volume expansion ratio of four weathering products

\begin{tabular}{lccc}
\hline mineral & Density $\left(\mathrm{g} / \mathrm{cm}^{3}\right)$ & Expansivity $(\%)$ & Water absorption expansion $(\%)$ \\
\hline rozenite & 2.2 & 425 & 147 \\
copiapite & 2.12 & 492 & 140 \\
ferricopiapite & 2.14 & 487 & 140 \\
jarosite & 2.12 & 485 & 144 \\
\hline
\end{tabular}

From Table 3, it indicates that the expansion effect of these sulfate products is significant obvious. On one hand, the precipitation of sulfate minerals may reduce the rock mass quality. On the other hand, the expansion acting on the rock mass repeatedly can affect the integrity of rock mass structure. This is the reason that as the salt materials heterogeneous distributed on the crack surface dissolved and precipitated repeatedly with the dissolution and evaporation, the expansion force make the rock fragments exfoliation along the cracks or the edges of crystallized minerals.

\section{Conclusions}

Based on the field investigations and laboratory tests of the mineral and chemical compositions of the black shale rocks and weathering products sampled in the Sanjiang region, the influence of acid corrosion caused by sulfide minerals oxidation on the rock mass and construction materials nearby was analyzed. Some conclusions are drawn as following: 1) The major mineral are quartz, clay mineral, dolomite, calcite and pyrite; the chemical compositions are silicon dioxide with high proportion, followed by aluminum oxide and calcium oxide. Major weathering products are sulfate minerals such as rozenite, copiapite, ferricopiapite and jarosite; 2) The oxidation process of black shale has acid corrosion. It is mainly manifested that mineral alteration leads to the transformation of some forming minerals into clay minerals. It is easy to form weak structure on the joint and fissures surfaces; 3) Acidic water and the expansive sulfate minerals produced during black shale oxidation have significant acid corrosion influence on the concrete materials.

\section{References}

[1] T.K. Dalai, S.K. Singh, J.R. Trivedi, S. Krishnaswami. Dissolved rhenium in the Yamuna river system and the Ganga in the Himalaya: role of black shale weathering on the budgets of Re, Os, and $\mathrm{U}$ in rivers and $\mathrm{CO}_{2}$ in the atmosphere, Geochimica et Cosmochimica Acta. 66: 29-43(2002)

[2] L.A. Jaffe, B. Peucker-Ehrenbrink, S.T. Petsch. Mobility of rhenium, platinum group elements and organic carbon during black shale weathering, Earth and Planetary Science Letters. 198: 339-353. (2002) 
[3] N. Thaulow, S. Sahu. Mechanism of concrete deterioration due to salt crystallization, Materials Characterization. 53: 123- 128. (2004)

[4] H. Haynes, R. O’Neill, M. Neff, P.K. Mehta. Salt weathering distress on concrete exposed to sodium sulfate environment, ACI Materials Journal. 105: 35-43. (2008)

[5] S.L. Brantley, C.F. Conrad. Analysis of Rates of Geochemical Reactions, Kinetics of water-rock interaction: New York, Springer, (2008) p.1-37.

[6] X. Liao, M. Chigira, Y. Matsushi, X. Wu. Investigation of water-rock interactions in Cambrian black shale via a flow-through experiment, Applied Geochemistry. 51: 65-78. (2014) 